\title{
Plasma retinol and tocopherol levels in relation to demographic, lifestyle and nutritional factors of plant origin in Greece
}

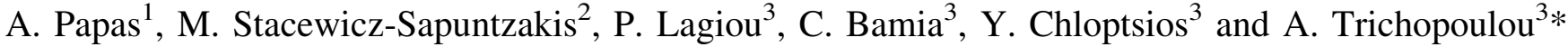 \\ ${ }^{1}$ Eastman Chemical Company, Kingsport, TN, USA \\ ${ }^{2}$ Department of Human Nutrition and Dietetics, College of Health and Human Development Sciences, University of Illinois \\ at Chicago, Chicago, IL, USA \\ ${ }^{3}$ Department of Hygiene and Epidemiology, University of Athens Medical School, 75 M.Asias St. GR-115 27, Goudi, Athens, \\ Greece
}

(Received 10 September 2001 - Revised 20 May 2002 - Accepted 6 September 2002)

\begin{abstract}
In the context of the Greek segment of the European Prospective Investigation into Cancer and Nutrition (EPIC) we have conducted a cross-sectional study to determine the effect of demographic, lifestyle and nutritional factors of plant origin on retinol, $\alpha$-tocopherol and $\gamma$-tocopherol. Study subjects were a random sample of forty-five men and sixty-eight women, aged 30-82 years, from the Greek EPIC cohort of 27953 volunteers. Analyses were done using linear regression models with the vitamin blood levels as dependent variables, and BMI, the intake of selected food items, total energy intake and a set of demographic factors as independent variables. Women had significantly lower plasma retinol levels $(P<0.006)$ than men. Both $\alpha$ - and $\gamma$-tocopherol levels increased by approximately $5 \%$ for every additional 5 years of age. Among dietary factors, intake of non-fruity vegetables was associated with increase, while intake of added lipids other than olive oil with decrease, of plasma retinol levels. BMI was positively associated with plasma $\gamma$-tocopherol only, while none of the foods or food groups investigated significantly affected the plasma levels of either of the two tocopherols. These findings need to be confirmed before attempts are made to use them in the context of explanatory mechanistic processes.
\end{abstract}

Retinol: $\alpha$-Tocopherol: $\gamma$-Tocopherol: Diet

There is overwhelming evidence that diet plays a critical role in the aetiology of cardiovascular diseases and several forms of cancer (National Research Council, 1989; Willett, 1994, 1998; Willett \& Trichopoulos, 1996; World Cancer Research Fund and American Institute for Cancer Prevention, 1997). Most of the evidence relies on whole foods and food groups, while the role of specific dietary constituents remains in most cases equivocal (Blumberg \& Block, 1994), except in the context of well-characterized nutritional deficiencies. Nevertheless, there is a general realization that characteristics of several micronutrients, including antioxidant properties, may play an important beneficial role in the aetiology of many chronic diseases (Papas, 1999). In Greece, the incidence of CHD and most forms of diet-related cancer is low and the consumption of foods rich in antioxidant and other compounds of plant origin is high (Trichopoulou et al. 1994), a concordance that contributes to the ecological evidence in support of the beneficial role of these foods on human health. Moreover, the variability of nutritional intake is high because several segments of the population adhere to the traditional Mediterranean diet, whereas others have adopted western dietary patterns. This variability facilitates the documentation of the association between plasma concentration of various nutrients and their dietary sources.

We have undertaken a study in a population sample of adult Greek men and women, in order to determine and quantify demographic, lifestyle and nutritional determinants of three important vitamins presumed to play a beneficial role in health: retinol, $\alpha$-tocopherol and $\gamma$-tocopherol.

\section{Materials and methods}

Plasma levels of retinol, $\alpha$-tocopherol and $\gamma$-tocopherol and several of demographic and nutritional factors were 
estimated in a random sample of forty-five men and sixtyeight women from the Greek European Prospective Investigation into Cancer and Nutrition (EPIC) cohort of 27953 volunteers. The individuals reporting use of nutritional supplements were excluded from the study.

EPIC is a multi-country prospective cohort study investigating the role of nutrition and other lifestyle and environmental factors in the aetiology of cancer and other chronic diseases (Riboli, 1992). In the context of the Greek component of the EPIC study, food frequency, lifestyle and medical history questionnaires were administered by specially trained interviewers to 11520 men and 16433 women, all apparently healthy, aged 30-82 years, and residing all over Greece. Somatometric measurements included weight and height, and blood samples were collected. Each participant signed an informed consent form before enrolment.

The semi-quantitative food frequency questionnaire was validated during the pilot phase of the study (Gnardellis et al. 1995; Katsouyanni et al. 1997). The questions probed the average frequency of consumption of approximately 150 food items and beverages over a period of 1 year. Standard portion sizes were used for the estimation of consumed quantities (Trichopoulou, 1992; Gnardellis et al. 1995). Intakes were expressed as daily averages, taking into account seasonal variation (Katsouyanni et al. 1997). Food items were considered individually, as well as in groups. Among the foods, we have chosen to examine the effect of tomatoes, fruity vegetables other than tomatoes, non-fruity vegetables (leafy, root, stalk, grain and pod vegetables, sprouts, mushrooms, onion, garlic), fruits, olive oil and other added lipids. Energy intake from all dietary sources was also taken into account, because it is a strong correlate of the intake of most foods and nutrients (Willett \& Stampfer, 1986).

Fasting blood samples were collected in $10 \mathrm{ml}$ vacutainers containing $10 \%(\mathrm{w} / \mathrm{v})$ citric acid and were centrifuged at $3600 \mathrm{rpm}$ at room temperature. The samples were stored at $-80^{\circ} \mathrm{C}$ and transported to the University of Illinois, Department of Nutrition and Medical Dietetics laboratory, Chicago, IL, packed in a Dewar container of liquid $\mathrm{N}_{2}$ at $-196^{\circ} \mathrm{C}$. Plasma $(0.2 \mathrm{ml})$ was deproteinized with an equal volume of absolute ethanol containing internal standard (retinyl acetate, $0.5 \mu \mathrm{g} / \mathrm{ml}$ ). The mixture was extracted twice with $2 \mathrm{ml}$ hexane containing butylated hydroxytoluene $(0.01 \%, \mathrm{w} / \mathrm{v})$, the extract evaporated to dryness under vacuum and reconstituted with $50 \mu \mathrm{l}$ stabilised ethyl ether and $150 \mu \mathrm{l}$ mobile phase. Of this extract, $10 \mu \mathrm{l}$ was injected into a HPLC system. The analytes were eluted isocratically at a flow rate of $1 \mathrm{ml} / \mathrm{min}$, using methanol-acetonitrile-tetrahydrofuran (50:45:5, by vol.) mobile phase and a Waters $150 \times 4.6 \mathrm{~mm}$ NovaPak column. The Waters 490 Programmable Multiwavelength Detector was used to detect retinoids $(325 \mathrm{~nm})$ and tocopherols $(295 \mathrm{~nm})$. This system is capable of routine separation of retinol, retinyl palmitate, retinyl acetate standard, $\gamma$-tocopherol and $\alpha$-tocopherol. External standards of these analytes were injected every $3 \mathrm{~h}$ to check the system's performance. The laboratory analyses data were processed using the Millennium computer program and corrected to account for both the recovery and any variability in HPLC performance. Concentrations of retinol, $\alpha$ - and $\gamma$-tocopherol were expressed as $\mu \mathrm{g} / \mathrm{l}$ in the plasma (Stacewicz-Sapuntzakis et al. 1987).

We developed linear regression models to evaluate demographic and dietary predictors of, alternatively, retinol, $\alpha$-tocopherol and $\gamma$-tocopherol. Because the distributions of $\alpha$-tocopherol and $\gamma$-tocopherol were positively skewed, we used log-transformed values of these dependent variables, whereas untransformed values were used for retinol. In all models, we regressed the dependent variables on the following variables: age (in years, continuously); gender; current smoking habits (current smokers $v$. non-current smokers, categorically); total energy intake (in $\mathrm{kJ} / \mathrm{d}$, continuously); BMI (in $\mathrm{kg} / \mathrm{m}^{2}$, continuously); the selected food items or groups, specifically tomatoes, fruity vegetables other than tomatoes, non-fruity vegetables, fruits, olive oil and added lipids other than olive oil (in $\mathrm{g} / \mathrm{d}$, continuously). The regression coefficients were expressed in relation to more meaningful increments, that is per 5 years of age, $2000 \mathrm{~kJ} / \mathrm{d}$ of energy intake, etc. as shown in the Tables. Introduction of squared terms for age did not substantially improve model fitness, nor did it materially affect the regression coefficients of the other covariates; thus, the parsimonious models were selected for presentation.

\section{Results}

Table 1 shows mean values and standard deviations of BMI $\left(\mathrm{kg} / \mathrm{m}^{2}\right)$, daily energy intake $(\mathrm{kJ})$, and intake of selected food items $(\mathrm{g} / \mathrm{d})$, as well as current smoking status by gender. About $45 \%$ of men and $30 \%$ of women were current smokers. Obesity was higher amongst women, particularly older women, and energy intake declined with age (data not shown). These results are descriptive, but also indicate that the characteristics of the sample are compatible with those of the underlying adult population.

Table 1. Body mass index, total energy intake, selected food intake and smoking status of forty-five men and sixty-eight women randomly selected from the Greek European Prospective Investigation into Cancer and Nutrition (EPIC) cohort (Mean values and standard deviations)

\begin{tabular}{|c|c|c|c|c|}
\hline & \multicolumn{2}{|c|}{ Men (n 45) } & \multicolumn{2}{|c|}{ Women (n 68) } \\
\hline & Mean & SD & Mean & SD \\
\hline BMI $\left(\mathrm{kg} / \mathrm{m}^{2}\right)$ & $29 \cdot 0$ & 4.9 & $29 \cdot 7$ & $6 \cdot 4$ \\
\hline Energy intake (kJ/d) & 9418 & 4184 & 7958 & 3213 \\
\hline Tomatoes $(\mathrm{g} / \mathrm{d})$ & 205 & 201 & 187 & 121 \\
\hline Fruity vegetables $(\mathrm{g} / \mathrm{d})^{*}$ & 158 & 104 & 180 & 120 \\
\hline $\begin{array}{l}\text { Non-fruity vegetables } \\
(\mathrm{g} / \mathrm{d}) \dagger\end{array}$ & 212 & 142 & 233 & 190 \\
\hline Fruits $(g / d)$ & 387 & 286 & 400 & 282 \\
\hline Olive oil (g/d) & 45 & 28 & 44 & 26 \\
\hline $\begin{array}{l}\text { Added lipids other than } \\
\text { olive oil }(g / d)\end{array}$ & 10 & 13 & 9 & 11 \\
\hline Current smokers: $n$ & \multirow{2}{*}{\multicolumn{2}{|c|}{$\begin{array}{c}20 \\
44 \cdot 4\end{array}$}} & \multicolumn{2}{|c|}{20} \\
\hline Percentage & & & & \\
\hline
\end{tabular}

* Other than tomatoes.

†Leafy, root, stalk, grain and pod vegetables, sprouts, mushrooms, onion, garlic. 
Table 2. Plasma retinol, $\alpha$ - and $\gamma$-tocopherol levels $(\mu \mathrm{g} / \mathrm{l})$, by gender, among forty-five men and sixty-eight women from the Greek European Prospective Investigation into Cancer and Nutrition (EPIC) study

(Mean values and standard deviations)

\begin{tabular}{|c|c|c|c|c|c|c|}
\hline & \multicolumn{2}{|c|}{$\begin{array}{l}\text { Men } \\
(n \text { 45) }\end{array}$} & \multicolumn{2}{|c|}{$\begin{array}{l}\text { Women } \\
(n 68)\end{array}$} & \multicolumn{2}{|c|}{$\begin{array}{l}\text { All subjects } \\
\quad(n 113)\end{array}$} \\
\hline & Mean & SD & Mean & SD & Mean & SD \\
\hline Retinol & 434 & 144 & 371 & 96 & 396 & 121 \\
\hline$\alpha$-Tocopherol & 11038 & 2213 & 11335 & 3081 & 11217 & 2761 \\
\hline$\gamma$-Tocopherol & 740 & 487 & 801 & 579 & 777 & 542 \\
\hline
\end{tabular}

In Table 2, mean values and standard deviations of plasma retinol, $\alpha$ - and $\gamma$-tocopherol levels $(\mu \mathrm{g} / \mathrm{l})$, by gender, among study subjects are presented. These results contribute to the definition of normal variation of the plasma levels of these vitamins. The data suggest that retinol is higher amongst men than amongst women.

Table 3 shows the multiple linear regression-derived partial coefficients, and corresponding $95 \% \mathrm{CI}$, for nondietary and dietary factors in relation to retinol. Women had significantly lower plasma retinol levels $(P<0 \cdot 006)$. Among dietary factors, intake of non-fruity vegetables was associated with increase, while intake of added lipids other than olive oil with decrease, of plasma retinol levels. None of the other investigated associations was statistically significant and suggestive effects may be discounted due to multiple comparisons.

Table 4 shows the percentage change of $\alpha$ - and $\gamma$-tocopherol plasma levels, respectively, and corresponding $95 \%$ $\mathrm{CI}$, per indicated increment of the independent variables. Both $\alpha$ - and $\gamma$-tocopherol levels increased by approximately $5 \%$ for every additional 5 years of age. BMI was positively associated with plasma $\gamma$-tocopherol only, while none of the foods or food groups investigated significantly affected the levels of either of the two tocopherols.

\section{Discussion}

Among the advantages of the present investigation is that the determination of the three vitamins in the plasma was done with adequate methodology; the utilisation of a sample size large enough to allow documentation of important associations; the determination of predictor variables using validated questionnaires (Gnardellis et al. 1995; Katsouyanni et al. 1997); the utilisation of a sample randomly selected from a well-defined study base. Moreover, the high variability of nutritional intakes in the Greek population increases the precision of the various estimates. Weaknesses of the study are ascertainment of diet through a semi-quantitative food frequency questionnaire rather than repeated $24 \mathrm{~h}$ recall measurements, inability to detect weak associations and the fact that the EPIC study had to be limited to volunteers.

Plasma retinol is considered to be a poor index of vitamin A status, unless liver stores are highly saturated or depleted (Willett, 1998). This fact, however, does not challenge the validity of significant associations, although it can be held responsible for false negative results. With respect to this vitamin, the principal findings were higher plasma levels amongst men than amongst women and a fairly strong positive association with non-fruity vegetables. The first of these findings is in agreement with several previous reports from populations of highly variable geographic origin (Nierenberg et al. 1989; Ito et al. 1991; Olmedilla et al. 1994; Morinobu et al. 1994; Virtanen et al. 1996). It seems reasonable to assume that there is a real gender difference, even though the modulating influences, possibly of hormonal nature, have not yet been identified. The positive association between nonfruity vegetables and plasma levels of retinol has not been previously reported and needs to be further investigated. It should be noted that this investigation has focused on foods widely consumed in Greece in the context of the traditional Mediterranean diet, whereas foods of animal origin, which are not characteristic of this diet, were not specifically investigated. It is also not clear why added lipids other than olive oil would be inversely associated with plasma retinol levels; indeed, it is possible that the association, although nominally significant, might have been a chance phenomenon generated by multiple comparisons.

Plasma levels of both $\alpha$ - and $\gamma$-tocopherol increase by

Table 3. Partial, linear regression-derived coefficients (b) for non-dietary and dietary predictors of retinol, simultaneously controlling for all independent variables (Regression-derived coefficients and $95 \%$ confidence intervals)

\begin{tabular}{|c|c|c|c|}
\hline Independent variable & Increment & $\mathrm{b}(\mu \mathrm{g} / \mathrm{l}$ per increment) & $95 \% \mathrm{Cl}$ \\
\hline \multicolumn{4}{|l|}{ Non-dietary factors } \\
\hline Age & 5 years & $-2 \cdot 1$ & $-14 \cdot 5,10 \cdot 4$ \\
\hline Gender & Females $v$. males & $-81 \cdot 5^{\star}$ & $-139 \cdot 6,-23 \cdot 4$ \\
\hline Current smoking status & Smokers $v$. non-smokers & $-23 \cdot 2$ & $-83 \cdot 5,37 \cdot 1$ \\
\hline \multicolumn{4}{|l|}{ Dietary factors } \\
\hline BMI & $1 \mathrm{~kg} / \mathrm{m}^{2}$ & $2 \cdot 8$ & $-1 \cdot 7,7 \cdot 4$ \\
\hline Energy intake & $2000 \mathrm{~kJ} / \mathrm{d}$ & $16 \cdot 8$ & $-17 \cdot 5,51 \cdot 1$ \\
\hline Tomatoes & $10 \mathrm{~g}$ & 3.73 & $-1 \cdot 0,8 \cdot 4$ \\
\hline Fruity vegetables other than tomatoes & $10 \mathrm{~g}$ & $-1 \cdot 22$ & $-5 \cdot 3,2 \cdot 9$ \\
\hline Non-fruity vegetables & $10 \mathrm{~g}$ & $5 \cdot 39^{*}$ & $1 \cdot 7,9 \cdot 1$ \\
\hline Fruits & $10 \mathrm{~g}$ & -0.08 & $-1 \cdot 2,1 \cdot 0$ \\
\hline Olive oil & $10 \mathrm{~g}$ & $-41 \cdot 6$ & $-87 \cdot 6,4 \cdot 4$ \\
\hline Added lipids other than olive oil & $10 \mathrm{~g}$ & $-63 \cdot 2$ & $-111 \cdot 3,-15 \cdot 2$ \\
\hline
\end{tabular}

${ }^{*}$ Changes were significant $(P<0.05)$. 
Table 4. Change in $\alpha$ - and $\gamma$-tocopherol per increment (or in comparison to the reference group) of non-dietary and dietary factors, simultaneously controlling for all independent variables (Percentage changes and $95 \%$ confidence intervals)

\begin{tabular}{|c|c|c|c|c|c|}
\hline \multirow[b]{2}{*}{ Independent variable } & \multirow[b]{2}{*}{ Increment } & \multicolumn{2}{|c|}{$\alpha$-Tocopherol } & \multicolumn{2}{|c|}{$\gamma$-Tocopherol } \\
\hline & & $\%$ change & $95 \% \mathrm{Cl}$ & $\%$ change & $95 \% \mathrm{Cl}$ \\
\hline \multicolumn{6}{|l|}{ Non-dietary factors } \\
\hline Age & 5 years & $4 \cdot 7^{*}$ & $2 \cdot 7,6 \cdot 8$ & $5 \cdot 4^{*}$ & $0.4,10.5$ \\
\hline Gender & Females $v$. males & $2 \cdot 4$ & $-7 \cdot 2,12 \cdot 0$ & $12 \cdot 6$ & $-11 \cdot 0,36 \cdot 2$ \\
\hline Current smoking status & Smokers $v$. non-smokers & -1.4 & $-11 \cdot 4,8 \cdot 6$ & $4 \cdot 6$ & $-19 \cdot 9,29 \cdot 1$ \\
\hline \multicolumn{6}{|l|}{ Dietary factors } \\
\hline BMI & $1 \mathrm{~kg} / \mathrm{m}^{2}$ & -0.1 & $-0.9,0.6$ & $3.1^{*}$ & $1 \cdot 3,5 \cdot 0$ \\
\hline Energy intake & $2000 \mathrm{~kJ} / \mathrm{d}$ & $-1 \cdot 1$ & $-6 \cdot 8,4 \cdot 6$ & 9.5 & $-4 \cdot 5,23 \cdot 4$ \\
\hline Tomatoes & $10 \mathrm{~g}$ & 0.1 & $-0.7,0.9$ & 0.7 & $-1 \cdot 2,2 \cdot 6$ \\
\hline Fruity vegetables other than tomatoes & $10 \mathrm{~g}$ & 0.3 & $-0.4,1.0$ & 0.1 & $-1.6,1.8$ \\
\hline Non-fruity vegetables & $10 \mathrm{~g}$ & -0.6 & $-1 \cdot 2,0.0$ & -0.1 & $-1.6,1.4$ \\
\hline Fruits & $10 \mathrm{~g}$ & -0.04 & $-0.2,0.1$ & -0.34 & $-0.8,0.1$ \\
\hline Olive oil & $10 \mathrm{~g}$ & 4.7 & $-2 \cdot 9,12 \cdot 2$ & -7.6 & $-26 \cdot 2,11 \cdot 1$ \\
\hline Added lipids other than olive oil & $10 \mathrm{~g}$ & $2 \cdot 0$ & $-5 \cdot 9,10$ & -7.8 & $-27 \cdot 3,11 \cdot 7$ \\
\hline
\end{tabular}

${ }^{\star}$ Changes were significant $(P<0.05)$.

approximately $5 \%$ for every additional 5 years of age. Positive associations have been reported in previous investigations (Hallfrisch et al. 1994), although some studies have reported no association (Morinobu et al. 1994). None of the food items or food groups was associated with plasma levels of either $\alpha$ - or $\gamma$-tocopherol, possibly because the unavoidable misclassification of nutrient intakes attenuates to non-detectable levels any existing association. It is also of interest that no association was found between current smoking status and either of the evaluated tocopherols. In contrast, there was a highly significant positive association between BMI and $\gamma$-tocopherol, an association that was not evident with respect to $\alpha$-tocopherol. Our results are in contrast with those from a study in Finland, where a positive association of $\alpha$-tocopherol with BMI was reported (Knekt et al. 1988).

It should be pointed out that plasma levels of the studied compounds were higher in our investigation than those reported in the literature (Lentner, 1984). However, even though this pattern is compatible with the low rates of CHD and several forms of cancer in the Greek population and the presumed beneficial effect of these compounds (Trichopoulos et al. 1991; Trichopoulou et al. 1999), such a comparison is not strictly legitimate given the variable procedures and standards used throughout the scientific community.

In conclusion, we have found that women have lower levels of retinol in comparison to men after adjustment for age and nutritional variables, and that non-fruity vegetable intake is positively associated with plasma retinol levels. Only age appears definitively positively associated with plasma $\alpha$ - and $\gamma$-tocopherol, whereas a positive association between BMI and $\gamma$-tocopherol requires confirmation in other datasets.

\section{Acknowledgements}

EPIC is coordinated by the International Agency for Research on Cancer (IARC) and supported by the Europe Against Cancer Programme of the European Commission.
The Greek segment of the EPIC study is also supported by the Greek Ministry of Health.

\section{References}

Blumberg J \& Block G (1994) The Alpha-Tocopherol, BetaCarotene Cancer Prevention Study in Finland. Nutrition Reviews 52, 242-245.

Gnardellis C, Trichopoulou A, Katsouyanni K, Polychronopoulos E, Rimm EB \& Trichopoulos D (1995) Reproducibility and validity of an extensive semi-quantitative Food Frequency Questionnaire among Greek school teachers. Epidemiology 6, 74-77.

Hallfrisch J, Muller DC \& Singh VN (1994) Vitamin A and E intakes and plasma concentrations of retinol, beta-carotene, and alpha-tocopherol in men and women of the Baltimore Longitudinal Study of Aging. American Journal of Clinical Nutrition 60, 176-182.

Ito Y, Shima Y, Ochiai J, Otani M, Sasaki R, Suzuki S, Hamajima N, Ogawa H \& Aoki K (1991) Effects of the consumption of cigarettes, alcohol and foods on serum concentrations of carotenoids, retinol and tocopherols in healthy inhabitants living in a rural area of Hokkaido. Nippon Eiseigaku Zasshi 46, 874-882.

Katsouyanni K, Rimm EB, Gnardellis C, Trichopoulos D, Polychronopoulos E \& Trichopoulou A (1997) Reproducibility and relative validity of an extensive semi-quantitative Food Frequency Questionnaire using dietary records and chemical markers among Greek school teachers. International Journal of Epidemiology 26, Suppl. 1, 118-127.

Knekt P, Seppanen R \& Aaran RK (1988) Determinants of serum alpha-tocopherol in Finnish adults. Preventive Medicine 17, $725-735$.

Lentner C (editor) (1984) Geigy Scientific Tables, vol. 3 - Physical Chemistry, Composition of Blood, Hematology, Somatometric Data, pp. 126-127. Basle, Switzerland: CIBA-GEIGY.

Morinobu T, Tamai H, Tanabe T, Murata T, Manago M, Mino M \& Hirahara F (1994) Plasma alpha-tocopherol, beta-carotene, and retinol levels in the institutionalized elderly individuals and in young adults. International Journal of Vitamin and Nutrition Research 64, 104-108.

National Research Council (1989) Diet and Health: Implications for Reducing Chronic Disease Risk. Washington, DC: National Academy Press.

Nierenberg DW, Stukel TA, Baron JA, Dain BJ \& Greenberg ER 
(1989) Determinants of plasma levels of beta-carotene and retinol. Skin Cancer Prevention Study Group. American Journal of Epidemiology 130, 511-521.

Olmedilla B, Granado F, Blanco I \& Rojas-Hidalgo E (1994) Seasonal and sex-related variations in six serum carotenoids, retinol, and alpha-tocopherol. American Journal of Clinical Nutrition 60, 106-110.

Papas A (editor) (1999) Antioxidant Status, Diet, Nutrition, and Health. Boca Raton, FL: CRC Press.

Riboli E (1992) Nutrition and Cancer: Background and rationale of the European Prospective Investigation into Cancer and Nutrition (EPIC). Annals of Oncology 3, 783-791.

Stacewicz-Sapuntzakis M, Bowen PE, Kikendall JW \& Burgess M (1987) Simultaneous determination of serum retinol and various carotenoids: their distribution in middle-aged men and women. Journal of Micronutrient Analysis 3, 27-45.

Trichopoulos D, Tzonou A, Katsouyanni K \& Trichopoulou A (1991) Diet and cancer: The role of case-control studies. Annals of Nutrition and Metabolism 35, Suppl. 1, 89-92.

Trichopoulou A (1992) Composition of Greek Foods and Dishes (in Greek and English). Athens, Greece: Athens School of Public Health.

Trichopoulou A, Lagiou P \& Trichopoulos D (1994) Traditional
Greek diet and coronary heart disease. Journal of Cardiovascular Risk 1, 9-15.

Trichopoulou A, Vasilopoulou E \& Lagiou A (1999) Mediterranean diet and coronary heart disease: are antioxidants critical? Nutrition Reviews 57, 253-255.

Virtanen SM, van't Veer P, Kok F, Kardinaal AF \& Aro A (1996) Predictors of adipose tissue carotenoid and retinol levels in nine countries. The EURAMIC Study. American Journal of Epidemiology 144, 968-979.

Willett W (1998) Nutritional Epidemiology, 2nd ed. New York: Oxford University Press.

Willett W \& Stampfer MJ (1986) Total energy intake: implications for epidemiologic analyses. American Journal of Epidemiology 124, 17-27.

Willett WC (1994) Diet and health: what should we eat? Science 264, 532-537.

Willett WC \& Trichopoulos D (1996) Summary of the evidence: Nutrition and cancer. Cancer Causes and Control 7, 178-180.

World Cancer Research Fund and American Institute for Cancer Prevention (1997) Food, Nutrition and the Prevention of Cancer: a Global Perspective. Washington, DC: World Cancer Research Fund and American Institute for Cancer Prevention. 